\title{
Stereotactic ablative radiotherapy for early- stage lung cancer following double lung transplantation
}

\author{
Hanbo Chen ${ }^{1}$, Jussi Tikkanen², R. Gabriel Boldt ${ }^{1}$ and Alexander V. Louie ${ }^{1 *}$
}

\begin{abstract}
Background: Development of primary lung cancer in donor lung post-lung transplantation is very rare, with few described cases. The safety of stereotactic ablative radiotherapy (SABR) for early-stage lung cancer arising from donor lung is unclear.

Case presentation: Herein, we present a case of a patient with a Stage IB adenocarcinoma arising from donor lung 8 years post-double lung transplantation, which was performed due to advanced emphysema. The patient was ineligible for surgical management due to chronic lung allograft dysfunction, which significantly compromised pulmonary function. Full dose SABR was delivered with curative intent after a discussion with the patient. The patient tolerated the treatment well, with one episode of subacute toxicity that resolved with treatment. There was no evidence of recurrence at 15 months post-treatment and the patient's pulmonary function did not deviate from the pre-SABR baseline.
\end{abstract}

Conclusions: SABR appears feasible for medically-inoperable early-stage primary lung adenocarcinoma in the setting of previous double-lung transplantation.

Keywords: Stereotactic body radiotherapy, Stereotactic ablative radiotherapy, Early stage, Non-small cell lung cancer, Lung transplantation

\section{Background}

The development of primary bronchogenic carcinoma following double-lung transplantation is very rare [1]. The use of stereotactic ablative radiotherapy (SABR) for medically-inoperable early-stage non-small cell lung cancer (NSCLC) arising from donor lung following double-lung transplantation has not been previously described. Here we present a case where SABR was used safely to treat an early-stage lung adenocarcinoma in a patient with a history of double-lung transplantation.

\section{Case presentation}

Our patient is a 60-year-old female with severe emphysema who underwent a double-lung transplant in 2008, donated from a 64-year-old female with a 25-pack-year smoking history, stopping in 1982. The explanted lungs

\footnotetext{
* Correspondence: dr.alexlouie@gmail.com

${ }^{1}$ Department of Radiation Oncology, London Health Sciences Centre, 790

Commissioners Road East, London, ON N6A 4L6, Canada

Full list of author information is available at the end of the article
}

showed signs of severe emphysema but no malignant features. Post-transplant imaging demonstrated a mild to moderate degree of emphysema in the donor lungs. The patient received triple-drug immunosuppression with cyclosporine A, azathioprine, and prednisone and remained well until 2014, when she developed posttransplant lymphoproliferative disorder (PTLD), requiring chemotherapy with cyclophosphamide/doxorubicin/ vincristine/prednisone-rituximab and discontinuation of azathioprine. While her PTLD is currently in remission, she subsequently developed chronic lung allograft dysfunction (CLAD) in 2015, with a marked decline in forced expiratory volume in $1 \mathrm{~s}$ (FEV1) from the posttransplant baseline of $3.1 \mathrm{~L}$ to $0.9 \mathrm{~L}$. Her FEV1 has been stable at $0.9 \mathrm{~L}$ since 2015.

In 2016, the patient presented with a solitary right upper lobe pulmonary nodule on routine computed tomography $(\mathrm{CT})$ scan. Following serial growth $(12 \mathrm{~mm})$

(C) The Author(s). 2018 Open Access This article is distributed under the terms of the Creative Commons Attribution 4.0 International License (http://creativecommons.org/licenses/by/4.0/), which permits unrestricted use, distribution, and reproduction in any medium, provided you give appropriate credit to the original author(s) and the source, provide a link to the Creative Commons license, and indicate if changes were made. The Creative Commons Public Domain Dedication waiver (http://creativecommons.org/publicdomain/zero/1.0/) applies to the data made available in this article, unless otherwise stated. 
on CT, the lung nodule was biopsied, revealing primary lung adenocarcinoma. The pathologic sample was negative for both the ALK fusion oncogene and EGFR mutation. Staging whole-body positron-emission tomographycomputerized tomography (PET-CT) scan and magnetic resonance (MR) scan of the brain did not reveal any evidence of distant metastases.

The patient was not a surgical candidate due to her poor pulmonary function $(\mathrm{FEV} 1=0.9 \mathrm{~L}, \mathrm{FEV} 1 /$ forced vital capacity $[\mathrm{FVC}]=39 \%$ ). She consented to undergo SABR. 4D-CT simulation was performed with vacuum cushion immobilization and the gross tumour volume (GTV) was contoured on the end-inspiratory and end-expiratory phases. No margin for microscopic disease extension was used. An internal target volume (ITV) was generated by merging the end-inspiratory and end-expiratory GTVs and a margin of $0.5 \mathrm{~cm}$ around the ITV was used to generate the planning target volume (PTV). Free-breathing treatment delivery was chosen due to minimal tumour respiratory motion. A risk-adapted schedule of $60 \mathrm{~Gy}$ in 8 fractions (biologically effective dose $\left.=105 \mathrm{~Gy}_{10}\right)$ was delivered every other day via a flattening filter-free volumetric modulated arc therapy technique using two 225-degree 6MV arcs on a linear accelerator. The dose was prescribed to the $80 \%$ isodose line, which encompassed $97.5 \%$ of the planning target volume. Planning was performed on Pinnacle [2] version 9.10 with heterogeneity correction, using published dose constraints for normal tissues [3]. The mean lung dose was $3.3 \mathrm{~Gy}$, and the volume of lung receiving $\geq 20$ Gy or more (V20) was $4.3 \%$. She completed radiotherapy in February 2017. Figure 1 shows selected images from the patient's radiotherapy plan.

Two months following completion of SABR, the patient was admitted to a community hospital with dyspnea, hypoxia, tachypnea and increased production of yellow sputum. She was afebrile, with no leukocytosis. A CT pulmonary angiogram did not demonstrate pulmonary embolism, though bilateral inflammatory opacities were suspicious for an infectious etiology. There was no evidence of an inflammatory process geometrically associated with the radiotherapy field suspicious for radiation pneumonitis. Sputum cultures did not identify a causative organism, though the patient was started on antibiotics empirically prior to obtaining a sputum sample and a viral cause was also possible. After discussion with the Respirology and Radiation Oncology services, she was started on cefuroxime and prednisone $50 \mathrm{mg}$ daily to cover all potential etiologies. Her respiratory function returned to baseline and she was discharged after 12 days of admission with a tapering schedule of prednisone. A follow-up CT 1 month later showed resolution of the bilateral opacities.

Since discharge, our patient's pulmonary function and subjective dyspnea have returned to pre-treatment levels and remained stable. Her most recent FEV1 was $0.9 \mathrm{~L}$, with FEV1/FVC of 37\% in March of 2018. Surveillance CTs at regular intervals demonstrated good local control, and post-treatment fibrotic pulmonary changes that

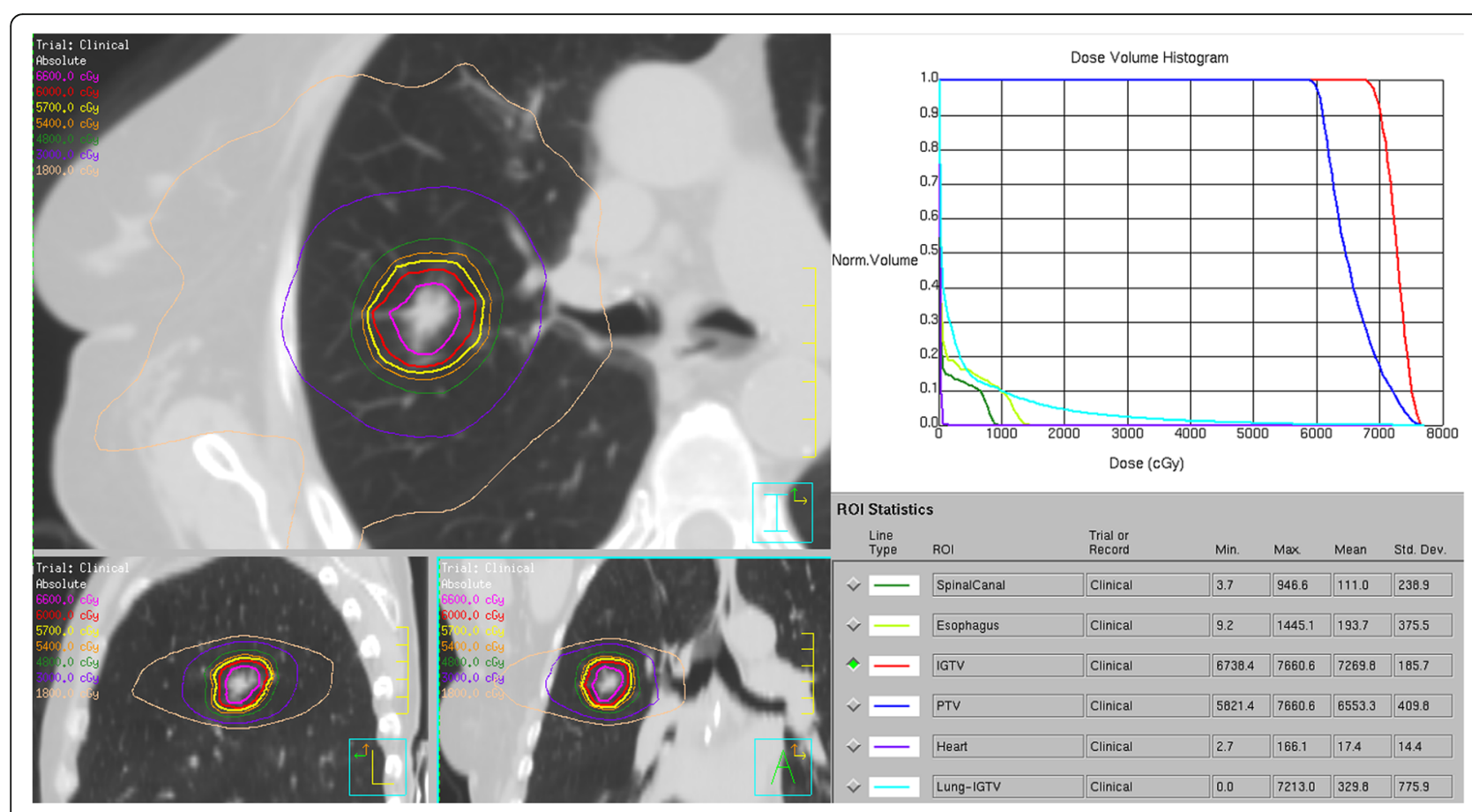

Fig. 1 Radiotherapy plan demonstrating isodose distributions and the dose-volume histogram for the targets (internal gross tumor volume (IGTV) the same as internal target volume (ITV) and planning target volume (PTV)) and organs-at-risk (spinal canal, esophagus, heart and lung) 
are common following SABR (Fig. 2). To date, the radiographic fibrotic changes do not harbor adverse features [2] that would be suggestive of recurrence and/or warrant PET-CT scan or repeat biopsy. The patient is alive and well as of May 2018.

\section{Discussion and conclusions}

Though patients are at higher risks of developing cancer post-solid organ transplantation [4], primary lung cancer developing in donor lung following lung transplantation is exceedingly rare. A recent review identified 14 patients among 11 sources between 2001 and 2012, with estimated prevalence ranging from 0.3 to $1 \%$ of lung transplant patients [1]. Another large series published after this review reported a prevalence of $4 / 462(0.9 \%)$ [5]. The reported cases include early and advanced NSCLC, as well as small cell lung cancer, treated with various modalities including radiotherapy, chemotherapy, surgery and best supportive care. While SABR was not employed for lung cancer arising from donor lung within any of these large reports, a literature search performed by our research team identified one other case of early-stage NSCLC arising from donor lung treated with SABR [6]. This patient previously received a single-lung transplant and SABR treatment was similarly well-tolerated, with the patient remaining disease-free after 22 months of follow-up. To our knowledge, our patient represents the first reported case where SABR was used to treat an early-stage

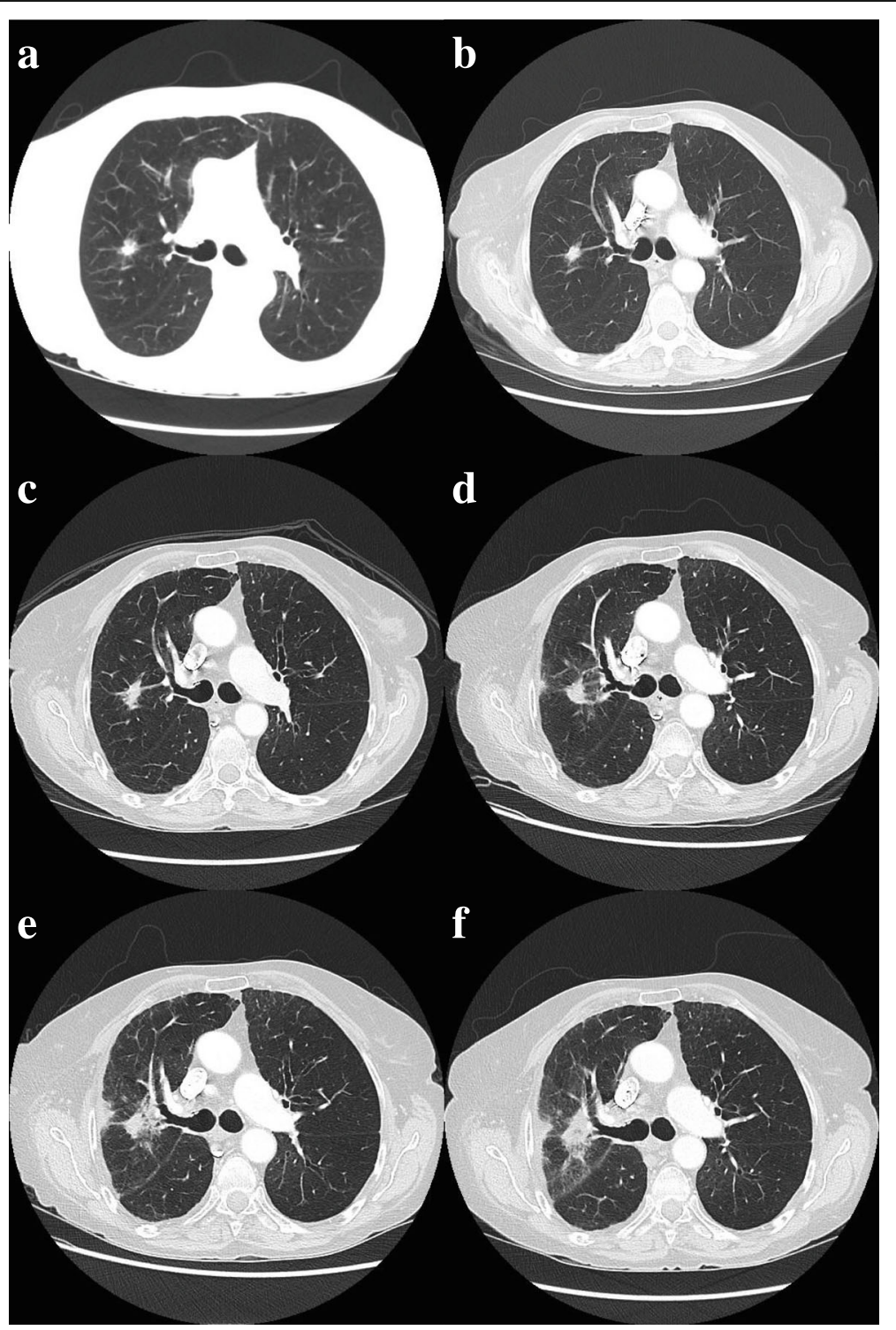

Fig. 2 CT images demonstrating the primary lesion a pre-treatment, b 3 months, c 6 months, $\mathbf{d} 9$ months and, e 12 months and $\mathbf{f} 15$ months post-treatment. Evolving post-radiation changes are observed 
NSCLC arising from donor lung following double-lung transplantation.

Guidelines for local treatment of early-stage NSCLC likely still apply for cancer arising from donor lung $[7,8]$. Surgery remains the mainstay of treatment in medically-operable Stage I/II NSCLC, while radiotherapy is indicated with radical intent for medically-inoperable early-stage disease and Stage III NSCLC. However, data is lacking on the interaction between immunosuppression and oncologic treatments. Traditional chemotherapy seems to be tolerated after transplantation [9], though there is a paucity of information regarding newer systemic therapy agents such as tyrosine kinase inhibitors and immunotherapeutic agents. The importance of an intact immune system in facilitating optimal radiation therapy response is being actively researched [10], though the precise implications of an immunosuppressed state during radiation therapy is not clearly understood.

The lung cancer described in the present case arose in lungs from an extended-criteria lung donor [11, 12]. These donors have a preponderance of being older, with some baseline impairment of pulmonary function and/or additional smoking history. Accepting potential donors with these less favorable characteristics allow for improved access to lung transplantation, and have become gradually more accepted within transplant centers over the past two decades [13]. Inclusion of extended-criteria lung donors appears to be associated with an increase in short-term adverse outcomes, although there does not appear to be a major impact on long-term outcomes compared to standard-criteria donors [14]. It is unclear whether extended-criteria donor lungs are associated with any increased risk of malignancy. Regardless, the overall low prevalence of primary lung cancer arising from donor lungs, despite immunosuppression, emphasizes the rarity of such a scenario. Such rarity, however, also makes prevention through screening difficult, due to the high number of expected false positives and low overall cost-effectiveness. Until more data is available, the benefits of expanding access to lung transplantation likely outweighs the relatively small risk of malignancy when using extended-criteria donor lungs.

The present case also highlights the difficulties faced by clinicians during follow-up for lung radiotherapy. In the subacute timeframe, it can be challenging to distinguish respiratory events due to co-existing pulmonary comorbidities from radiation pneumonitis. Differential etiologies such as viral/bacterial pneumonia, chronic obstructive pulmonary disease exacerbation, and interstitial lung disease exacerbation should be addressed concurrently based on clinical features. In the long term, identifying recurrences where the perilesional lung becomes fibrotic is a unique challenge post-SABR. Any potentially adverse features [2] should be interpreted through multidisciplinary collaboration between thoracic radiation oncologists and radiologists. Of note, the development of computerized algorithms (radiomics) to identify subtler radiographic features in this setting is an active area of research [15].

\section{Conclusion}

We demonstrate the feasibility and safety of full-dose SABR for an early-stage NSCLC arising from donor lung in a double-lung transplant recipient. A larger repertoire of patients with adequate follow-up is required to determine SABR's oncologic effectiveness in this population of chronically immunosuppressed patients.

\section{Abbreviations}

CLAD: Chronic lung allograft dysfunction; CT: Computed tomography; FEV1: Forced expiratory volume in $1 \mathrm{~s}$; FVC: Forced vital capacity; MR: Magnetic resonance; NSCLC: Non-small cell lung cancer; PET-CT: Positron emission tomography-computed tomography; PTLD: Post-transplant lymphoproliferative disorder; SABR: Stereotactic ablative radiotherapy; V20: Volume receiving at least $20 \mathrm{~Gy}$

\section{Authors' contributions}

RGB performed a literature review and was involved in the inception of the study. HC, AVL and JT were involved in collecting information about the patient and were major contributors for writing the manuscript. All authors read and approved the final manuscript.

Ethics approval and consent to participate

Not applicable

Consent for publication

We declare that our patient has provided consent for publication.

\section{Competing interests}

AVL declares speaker's honoraria from Varian Medical Systems. HC, JT and RGB declare no competing interests.

\section{Publisher's Note}

Springer Nature remains neutral with regard to jurisdictional claims in published maps and institutional affiliations.

\section{Author details}

${ }^{1}$ Department of Radiation Oncology, London Health Sciences Centre, 790 Commissioners Road East, London, ON N6A 4L6, Canada. ${ }^{2}$ Multi-Organ Transplant Program, Toronto General Hospital, University Health Network, 200 Elizabeth Street, Toronto, ON M5G 2C4, Canada.

Received: 29 June 2018 Accepted: 27 July 2018

Published online: 07 August 2018

\section{References}

1. Olland AB, Falcoz PE, Santelmo N, Kessler R, Massard G. Primary lung cancer in lung transplant recipients. Ann Thorac Surg. 2014;98(1):362-71.

2. Huang $K$, Senthi S, Palma DA, et al. High-risk CT features for detection of local recurrence after stereotactic ablative radiotherapy for lung cancer. Radiother Oncol. 2013;109(1):51-7.

3. Adebahr S, Collette S, Shash E, et al. LungTech, an EORTC phase II trial of stereotactic body radiotherapy for centrally located lung tumours: a clinical perspective. Br J Radiol. 2015;88(1051):20150036.

4. Chapman JR, Webster AC, Wong G. Cancer in the Transplant Recipient. Cold Spring Harb Perspect Med. 2013;3(7):a015677.

5. Grewal AS, Padera RF, Boukedes $S$, et al. Prevalence and outcome of lung cancer in lung transplant recipients. Respir Med. 2015;109(3):427-33.

6. Oskan F, Ganswindt U, Belka C, Manapov F. Primary non-small cell lung cancer in a transplanted lung treated with stereotactic body radiation therapy. A case study. Strahlenther Onkol. 2014;190(4):411-5. 
7. Howington JA, Blum MG, Chang AC, Balekian AA, Murthy SC. Treatment of stage I and II non-small cell lung cancer: diagnosis and management of lung cancer, 3rd ed: American College of Chest Physicians evidence-based clinical practice guidelines. Chest. 2013;143(5 Suppl):e278S-313S.

8. Postmus PE, Kerr KM, Oudkerk M, et al. Early and locally advanced nonsmall-cell lung cancer (NSCLC): ESMO Clinical Practice Guidelines for diagnosis, treatment and follow-upt. Ann Oncol. 2017;28(suppl_4):iv1-iv21.

9. Horn M, Phebus C, Blatt J. Cancer chemotherapy after solid organ transplantation. Cancer. 1990;66(7):1468-71.

10. Walle T, Martinez Monge R, Cerwenka A, Ajona D, Melero I, Lecanda F. Radiation effects on antitumor immune responses: current perspectives and challenges. Ther Adv Med Oncol. 2018;10 https:/doi.org/10.1177/1758834017742575.

11. Botha P. Extended donor criteria in lung transplantation. Curr Opin Organ Transplant. 2009;14(2):206-10.

12. Chaney J, Suzuki Y, Cantu E 3rd, van Berkel V. Lung donor selection criteria. J Thorac Dis. 2014;6(8):1032-8.

13. Somers J, Ruttens $\mathrm{D}$, Verleden $\mathrm{SE}$, et al. A decade of extended-criteria lung donors in a single center: was it justified? Transpl Int. 2015;28(2):170-9.

14. Schiavon M, Falcoz PE, Santelmo N, Massard G. Does the use of extended criteria donors influence early and long-term results of lung transplantation? Interact Cardiovasc Thorac Surg. 2012;14(2):183-7.

15. Mattonen SA, Palma DA, Johnson C, et al. Detection of local Cancer recurrence after stereotactic ablative radiation therapy for lung Cancer: physician performance versus Radiomic assessment. Int J Radiat Oncol Biol Phys. 2016;94(5):1121-8.

Ready to submit your research? Choose BMC and benefit from:

- fast, convenient online submission

- thorough peer review by experienced researchers in your field

- rapid publication on acceptance

- support for research data, including large and complex data types

- gold Open Access which fosters wider collaboration and increased citations

- maximum visibility for your research: over $100 \mathrm{M}$ website views per year

At BMC, research is always in progress.

Learn more biomedcentral.com/submissions 